\title{
Determinants of spironolactone binding specificity in the mineralocorticoid receptor
}

\author{
F M Rogerson, Y-Z Yao, B J Smith ${ }^{1}$, N Dimopoulos and P J Fuller \\ Prince Henry's Institute of Medical Research, P.O. Box 5152, Clayton, Victoria 3168, Australia \\ ${ }^{1}$ Walter and Eliza Hall Institute, Parkville, Victoria 3050, Australia
}

(Requests for offprints should be addressed to F M Rogerson; Email: fraser.rogerson@ @med.monash.edu.au)

\begin{abstract}
Spironolactone is a mineralocorticoid receptor (MR) antagonist in clinical use. The compound has a very low affinity for the glucocorticoid receptor (GR). Determinants of binding specificity of spironolactone to the MR were investigated using chimeras created between the ligand-binding domains (LBDs) of the MR and the GR. These chimeras had previously been used to investigate aldosterone binding specificity to the MR. Spironolactone was able to compete strongly for $\left[{ }^{3} \mathrm{H}\right]$-aldosterone and $\left[{ }^{3} \mathrm{H}\right]$-dexamethasone binding to a chimera containing amino acids $804-874$ of the MR, and weakly for $\left[{ }^{3} \mathrm{H}\right]$-dexamethasone binding to a chimera containing amino acids $672-803$ of the MR. Amino acids 804-874 were also critical for aldosterone binding specificity. Models of the MR LBD bound to aldosterone and spironolactone were created based on the crystal structure of the progesterone receptor LBD. The ligand-binding pocket of the MR LBD model consisted of 23 amino acids and was predominantly hydrophobic in nature. Analysis of this model in light of the experimental data suggested that spironolactone binding specificity is not governed by amino acids in the ligand-binding pocket.
\end{abstract}

Journal of Molecular Endocrinology (2003) 31, 573-582

\section{Introduction}

Spironolactone is an antagonist of the mineralocorticoid receptor (MR) used in the treatment of hypertension due to primary aldosteronism and in conditions of secondary hyperaldosteronism such as cardiac or hepatic failure (Doggrell \& Brown 2001). The clinical use of spironolactone was placed in the spotlight with the results of the RALES trial (Pitt et al. 1999), which demonstrated that the addition of spironolactone to the treatment regimen of patients with severe heart failure led to a $30 \%$ decrease in mortality. Unfortunately, spironolactone has side-effects due to its cross-reactivity with the related androgen receptor, which have limited its clinical usefulness as an anti-mineralocorticoid. There is a need for better, more specific MR antagonists, and therefore a need to better understand ligand binding to the MR.

The MR belongs to the nuclear hormone receptor superfamily of ligand-dependent transcription factors. As with other members of the family, the receptor structure can be divided into three major functional domains (Rogerson \& Fuller 2000). The first of these is the N-terminal domain which contains an 'activation function' (AF-1) involved in transcriptional activation (Rupprecht et al. 1993a, Govindan \& Warriar 1998, Fuse et al. 2000). In the middle of the protein is the DNA-binding domain (DBD) which binds to specific DNA sequences on target genes and is also responsible for receptor homodimerisation (Liu et al. 1996). C-terminal to the $\mathrm{DBD}$ is the ligand-binding domain (LBD) which has sequences involved in ligand binding (Fagart et al. 1998), transcriptional activation (AF-2) (Rupprecht et al. 1993a) and heat-shock protein (HSP) binding (Eisen \& Harmon 1986, Nemoto et al. 1993). The $\mathrm{AF}-2$ region of the MR, like other nuclear hormone receptors, functions by interacting with coactivator proteins (Hong et al. 1997, Knutti et al. 2000).

The critical function of the LBD is the binding of ligand. In the absence of ligand, the MR exists predominantly in the cytoplasm in a complex with a number of HSPs (Nemoto et al. 1993). The binding of HSPs keeps the receptor in an inactive 
state, and also maintains the LBD in a conformation that promotes high-affinity ligand binding (Eisen \& Harmon 1986). The binding of ligand alters the conformation of the receptor and displaces the HSPs, which exposes sequences involved in receptor dimerisation, nuclear localisation and DNA binding. These conformational changes are also required for the activation of the AF-2 region.

Of the steroid hormone receptors, the MR has the most sequence identity with the glucocorticoid receptor (GR) (Arriza et al. 1987). This is reflected in the overlapping binding specificities of the two receptors. Both receptors bind cortisol and corticosterone with high affinity, whereas only the MR binds aldosterone with high affinity (Funder et al. 1988). The synthetic GR agonist dexamethasone also binds to the MR with relatively high affinity (Arriza et al. 1987, Rupprecht et al. 1993b) although it does not activate the MR with the same potency as it does the GR (Arriza 1991, Rupprecht et al. 1993b). Spironolactone has a very low affinity for the GR (Couette et al. 1992b). The structures of aldosterone and spironolactone are shown in Fig. 1. Apart from the steroid backbone, the two structures are quite dissimilar: the aldosterone molecule contains a hemiketal side-chain between $\mathrm{C}_{11}$ and $\mathrm{C}_{18}$, whereas spironolactone contains a lactone ring at $\mathrm{C}_{17}$ and a sulfhydryl ester side-chain at $\mathrm{C}_{7}$. In previous work we investigated structural determinants of aldosterone binding specificity using chimeras created between the LBDs of the MR and GR (Rogerson et al. 1999). We identified a region in the MR LBD, between amino acids 804 and 874, that is critical for the specificity of aldosterone binding to the MR. In the present study, we have used the same chimeras to investigate the binding of spironolactone to the MR. We have found that spironolactone binds strongly to a chimera containing amino acids 804-874 of the $\mathrm{MR}$, and weakly to a chimera containing amino acids $672-803$ of the MR. These results are discussed in relation to a model of the MR LBD structure created from the crystal structure of the progesterone receptor (PR) LBD.

\section{Materials and methods}

\section{Expression and reporter constructs}

Creation of the MR:GR LBD chimeras is described in detail elsewhere (Rogerson et al. 1999).

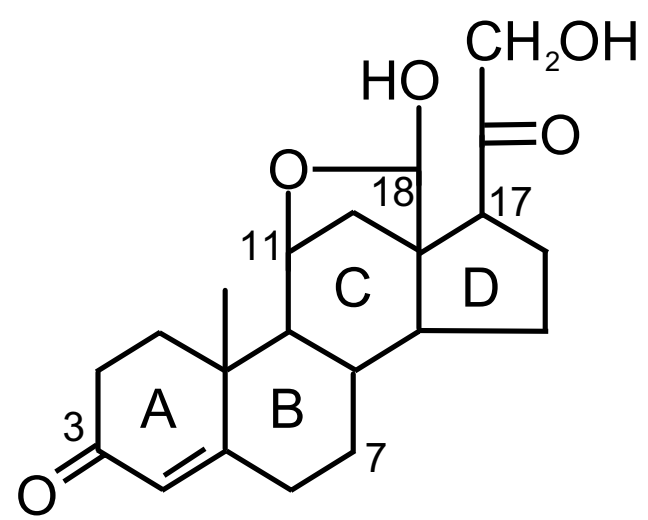

ALDOSTERONE

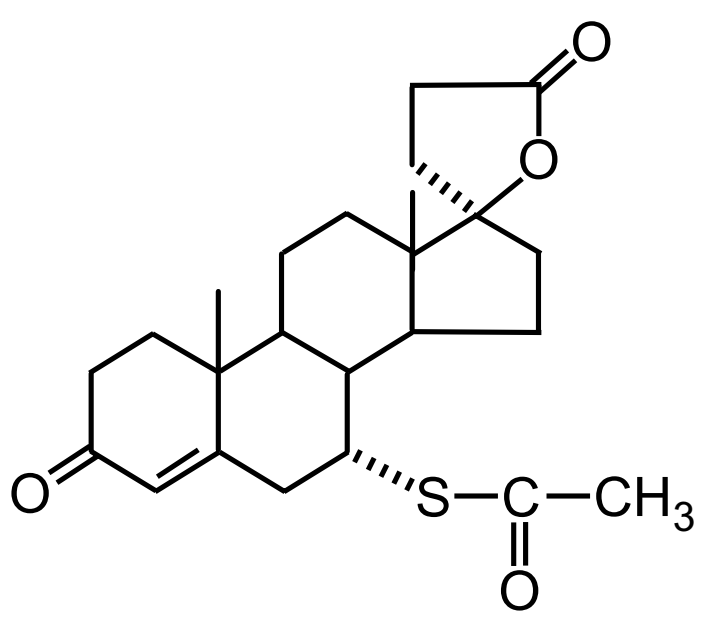

SPIRONOLACTONE

Figure 1 The structures of aldosterone and spironolactone. The positions of various backbone carbons mentioned in the text are labelled on the aldosterone structure using the conventional nomenclature, as are the identities of the A, B, C and $D$ rings.

The chimeras were created by dividing the LBD into four segments. Each chimera is designated by the identity of each particular section where 'M' indicates MR sequence and ' $G$ ' indicates GR sequence. In all cases the LBD was placed into an expression vector containing the N-terminal domain and the DNA-binding domain of the GR. The full-length receptor sequences were ligated into the pcDNA3 $1(+)$ mammalian expression 
vector (Invitrogen Life Technologies, Carlsbad, CA, USA).

\section{Ligand-binding competition assays}

Ligand-binding assays were performed in transfected COS-1 cells using either $\left[1,2,4,6,7-{ }^{3} \mathrm{H}\right]$ dexamethasone (Amersham Biosciences, Amersham, Bucks, UK) or $\left[1,2,6,7-{ }^{3} \mathrm{H}\right]$-aldosterone (Amersham Biosciences). Cells were grown at $37^{\circ} \mathrm{C}$ in Dulbecco's modified Eagles' medium (DMEM) supplemented with $1 \mathrm{mM}$ glutamine, non-essential amino acids, $1 \%$ penicillin-streptomycin and $10 \%$ fetal bovine serum (FBS). The cells were trypsinised and replated in six-well plates at a density of $2 \times 10^{5}$ cells/well. After 20-24 h, the cells were transfected with the expression plasmid using Fugene 6 (Roche Molecular Biochemicals, Indianapolis, IN, USA) and then incubated overnight in DMEM $+2 \%$ FBS. The medium was replaced with DMEM $1 \mathrm{~h}$ before the ligand-binding assay. The cells were washed three times with ice-cold phosphatebuffered saline (PBS) then ${ }^{3} \mathrm{H}$-labelled steroid was added in DMEM. Non-specific binding was assessed by adding a 500-fold excess of nonradioactive steroid. The cells were incubated at $37^{\circ} \mathrm{C}$ for $1 \mathrm{~h}$. Cells were then washed three times with ice-cold PBS and then lysed using $1 \mathrm{M}$ $\mathrm{NaOH}$. The suspension was added to scintillant and radioactivity was measured in a Packard 2500 TR liquid scintillation counter. Scatchard analysis of $\left[{ }^{3} \mathrm{H}\right]$-dexamethasone binding was performed using $25,10,4,1 \cdot 6,0.64$ and $0.26 \mathrm{nM}$ radioligand. The ability of spironolactone to compete for $\left[{ }^{3} \mathrm{H}\right]$-dexamethasone binding was assessed using 1-, 5-, 10- and 50-fold molar excesses of the concentration of radioligand. The ability of spironolactone to compete for $\left[{ }^{3} \mathrm{H}\right]$-aldosterone binding was assessed using 10-, 100- and 500-fold molar excesses of the concentration of radioligand. Statistical significance was measured by the Games-Howell analysis of variance test (heterogeneous variances) using the GB-STAT software (Dynamic Microsystems Inc., Houston, TX, USA).

\section{Model of the MR LBD structure based on the PR LBD crystal structure}

A model of the MR LBD dimer was generated using the homology package within the InsightII suite from Molecular Simulations Inc., San Diego,
CA, USA (1997), based on the structure of the human PR LBD dimer (Protein Data Base (PDB) identification code la28 (Williams \& Sigler 1998)). This structure was subsequently subjected to minimisation using the Discover 2.98 program (Accelrys Inc., San Diego, CA, USA). The CFF91 force field was applied, using an electrostatic cutoff distance of $12 \cdot 0 \AA$. Minimisation followed a protocol of initial steepest descents until the maximum derivative was less than $10 \cdot 0$, followed by conjugate gradients until the maximum derivative was less than $0.001(\mathrm{kcal} / \mathrm{mol} \AA)$. During this procedure, the side-chain heavy atoms of those amino acids conserved between PR and MR were held fixed in their positions in the X-ray crystal structure of PR. These constraints (rigid) were applied to prevent the model structure deviating significantly from the PR template. In addition, a water molecule in the ligand-binding site was also fixed. The ligands, aldosterone and spironolactone, were constructed from the progesterone bound in PR, and were not constrained during the minimisation.

\section{Results}

\section{Spironolactone competition for $\left[{ }^{3} \mathrm{H}\right]$-dexamethasone binding}

To examine ligand binding to the MR, we created a series of chimeras between the MR and GR LBDs (Rogerson et al. 1999). The chimeras were designed by dividing the LBDs into four equivalent sections. They were named using a four letter code, corresponding to the four regions, in which ' $\mathrm{M}$ ' denotes MR sequence and ' $G$ ' denotes GR sequence. To examine spironolactone binding, the chimeras MGGG (MR amino acids 672-803), GMGG (MR amino acids 804-874), GGMG (MR amino acids 875-932) and GGGM (MR amino acids 933-984) were used. Spironolactone binding to these chimeras was examined by its ability to compete for the binding of $\left[{ }^{3} \mathrm{H}\right]$-dexamethasone, as $\left[{ }^{3} \mathrm{H}\right]$-dexamethasone binds to all the chimeras, whereas $\left[{ }^{3} \mathrm{H}\right]$-aldosterone only binds to the GMGG chimera (Rogerson et al. 1999). The binding experiments were performed in transfected COS- 1 cells that lack endogenous MR and GR.

Before analysis of spironolactone binding, the affinity $\left(K_{\mathrm{d}}\right)$ of $\left[{ }^{3} \mathrm{H}\right]$-dexamethasone binding to the GR, MR LBD, MGGG, GMGG, GGMG and GGGM chimeras was determined (Table 1). Only 
MR LBD

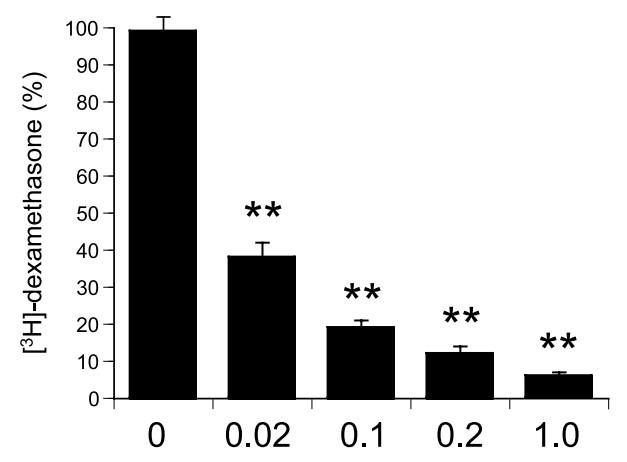

\section{GR}

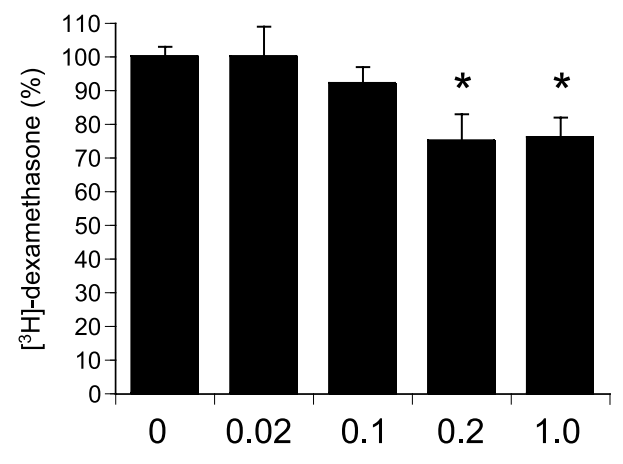

SPIRONOLACTONE $(\mu \mathrm{M})$

\section{MGGG}

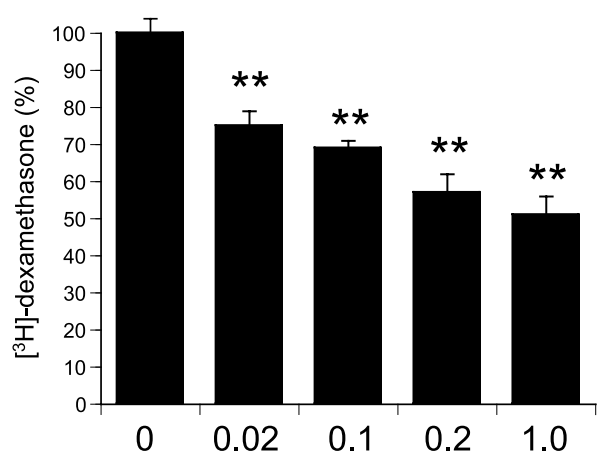

\section{GMGG}

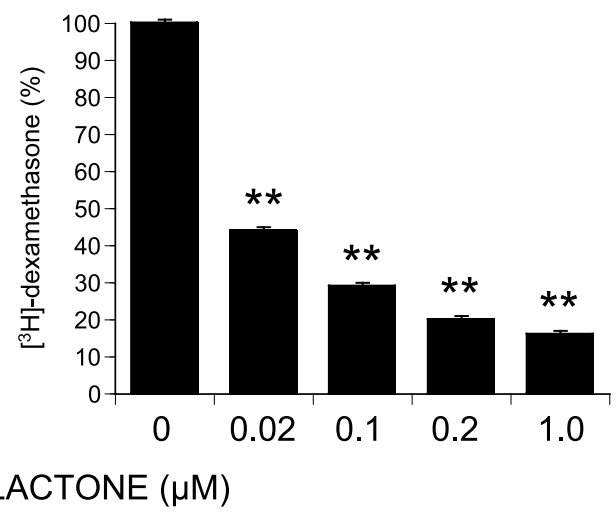

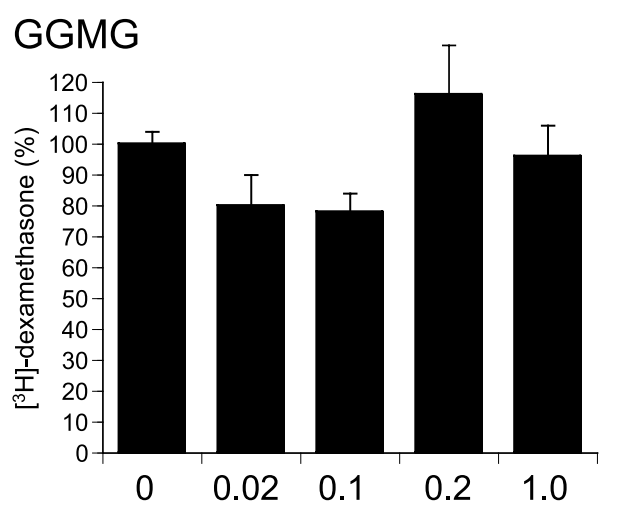

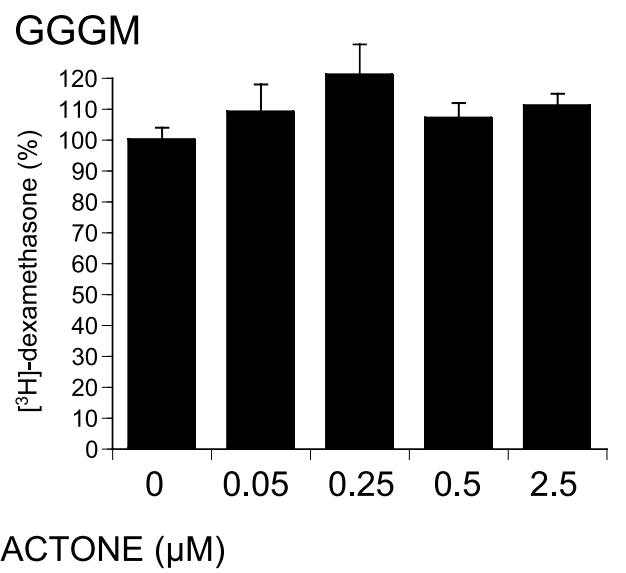

Figure 2 Spironolactone competition for $\left[{ }^{3} \mathrm{H}\right]$-dexamethasone binding to MR LBD, GR, and the chimeras MGGG, GMGG, GGMG and GGGM. Ligand-binding studies were performed in COS-1 transformed monkey kidney fibroblast cells using a concentration of $20 \mathrm{nM}\left[{ }^{3} \mathrm{H}\right]$-dexamethasone for all constructs except GGGM, where $50 \mathrm{nM}$ $\left[{ }^{3} \mathrm{H}\right]$-dexamethasone was used. The concentrations of spironolactone used were defined by the concentration of $\left[{ }^{3} \mathrm{H}\right]$-dexamethasone. Non-specific binding was assessed using a 500 -fold excess of dexamethasone. The results are expressed as a percentage of the binding in the absence of spironolactone. The graphs show the mean \pm S.E.M. from the results of two independent experiments $(n=6)$. ${ }^{*} P<0.05$, relative to assay containing no spironolactone; ${ }^{\star \star} P<0 \cdot 01$, relative to assay containing no spironolactone. 


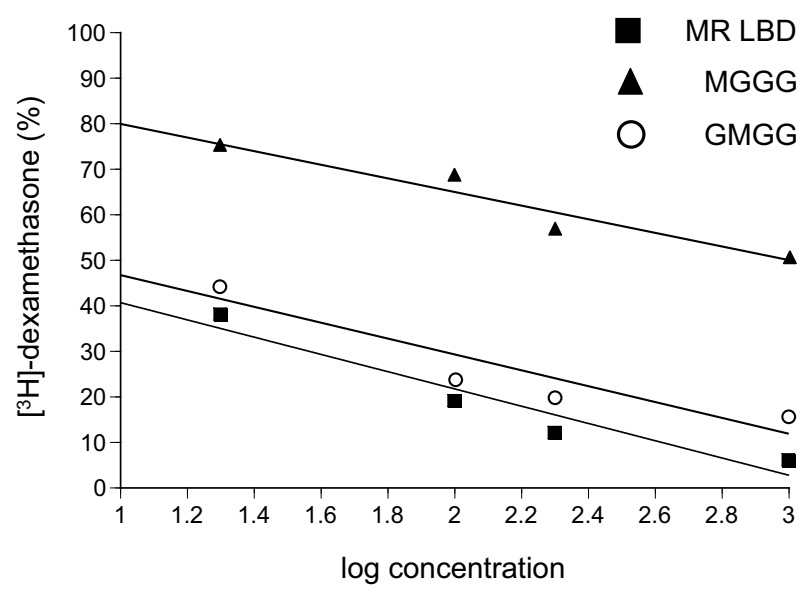

\begin{tabular}{lc} 
construct & $\mathbf{I C}_{\mathbf{5 0}}(\mathbf{n M})$ \\
\hline MR LBD & 3 \\
MGGG & 750 \\
GMGG & 7
\end{tabular}

Figure 3 Estimation of $\mathrm{IC}_{50}$ values for $\left[{ }^{3} \mathrm{H}\right]$-dexamethasone binding to the MR LBD and MGGG and GMGG chimeras.

one binding site was identified in each of the Scatchard analyses. Table 1 also shows $B_{\max }$ values for $\left[{ }^{3} \mathrm{H}\right]$-dexamethasone binding to the constructs, demonstrating that all are expressed at high levels. A $K_{\mathrm{d}}$ value of $11 \pm 3 \mathrm{nM}$ was obtained for $\left[{ }^{3} \mathrm{H}\right]$-dexamethasone binding to the $\mathrm{GR}$ in the whole-cell binding assay. This value compares with $K_{\mathrm{d}}$ values of $2-3 \mathrm{nM}$ obtained in studies using cytosols derived from transfected COS cells (Roux et al. 1996, Giannoukos et al. 1999), suggesting that the COS-1 cells have only a minor affect on the access of the radioligand to the receptor. The $K_{\mathrm{d}}$ values for $\left[{ }^{3} \mathrm{H}\right]$-dexamethasone binding to the GR

Table $1 K_{\mathrm{d}}$ and $\mathrm{B}_{\max }$ measurements of $\left[{ }^{3} \mathrm{H}\right]$-dexamethasone binding to constructs used in the study. Each measurement was performed twice. Values are means \pm S.E.M.

\begin{tabular}{|c|c|c|}
\hline & $\boldsymbol{K}_{\mathrm{d}}(\mathrm{nM})$ & $\begin{array}{l}\mathbf{B}_{\max } \\
\left(\mathrm{pmol} / 2 \times 10^{5} \text { cells }\right)\end{array}$ \\
\hline \multicolumn{3}{|l|}{ Construct } \\
\hline GR & $11 \pm 3$ & $60 \pm 10$ \\
\hline MR LBD & $8 \pm 1$ & $220 \pm 20$ \\
\hline MGGG & $21 \pm 1$ & $40 \pm 40$ \\
\hline GMGG & $15 \pm 5$ & $70 \pm 35$ \\
\hline GGMG & $10 \pm 1$ & $200 \pm 140$ \\
\hline GGGM & $54 \pm 4$ & $60 \pm 40$ \\
\hline
\end{tabular}

www.endocrinology.org and the MR LBD were very similar, which is consistent with a study examining the ability of dexamethasone to compete for $\left[{ }^{3} \mathrm{H}\right]$-aldosterone binding to the MR and $\left[{ }^{3} \mathrm{H}\right]$-dexamethasone binding to the GR (Rupprecht et al. 1993b). In all cases, the Hill coefficients were very close to 1 , suggesting no co-operativity in binding. On the basis of these results, the spironolactone competition experiments were performed using $20 \mathrm{nM}$ $\left[{ }^{3} \mathrm{H}\right]$-dexamethasone for the GR, the MR LBD and the MGGG, GMGG and GGMG chimeras, and $50 \mathrm{nM}\left[{ }^{3} \mathrm{H}\right]$-dexamethasone for the GGGM chimera. Spironolactone was added in 1-, 5-, 10and 50-fold molar excesses of the concentration of radioligand used for each construct.

Figure 2 shows spironolactone competition for $\left[{ }^{3} \mathrm{H}\right]$-dexamethasone binding to the MR LBD, the GR and the MGGG, GMGG, GGMG and GGGM chimeras. As expected, spironolactone competed strongly for $\left[{ }^{3} \mathrm{H}\right]$-dexamethasone binding to the MR LBD. In contrast, spironolactone competed very weakly for $\left[{ }^{3} \mathrm{H}\right]$-dexamethasone binding to the GR. One micromolar spironolactone reduced $\left[{ }^{3} \mathrm{H}\right]$-dexamethasone binding to the GR by approximately 25\%. A similar result was obtained in another study examining the ability of spironolactone to compete for $\left[{ }^{3} \mathrm{H}\right]$ dexamethasone binding to the GR (Couette et al. 1992b). Spironolactone competed strongly for $\left[{ }^{3} \mathrm{H}\right]$-dexamethasone binding to the GMGG chimera, which contains amino acids 804-874 of the MR. Spironolactone competed weakly, but significantly, for $\left[{ }^{3} \mathrm{H}\right]$-dexamethasone binding to the MGGG chimera, which contains amino acids 672-803 of the MR. In contrast, spironolactone did not appear to bind to the GGMG and GGGM chimeras at the concentrations used. The approximate $\mathrm{IC}_{50}$ values of spironolactone competition for $\left[{ }^{3} \mathrm{H}\right]$-dexamethasone binding to the MR LBD and MGGG and GMGG chimeras were determined by plotting the percentage binding against the log of the concentration of spironolactone (Fig. 3). The $\mathrm{IC}_{50}$ values shown in Fig. 3 are derived from the equations of the lines. The $\mathrm{IC}_{50}$ value of $3 \mathrm{nM}$ obtained for the MR LBD was in very good agreement with the $K_{\mathrm{d}}$ value of $3 \mathrm{nM}$ calculated for $\left[{ }^{3} \mathrm{H}\right]$-spironolactone binding to the MR in chicken intestine cytosols (Couette et al. 1992a). This also suggested that COS-l cells do not affect access of spironolactone to the receptor in the binding assay. The $\mathrm{IC}_{50}$ value of spironolactone binding 


\section{MR LBD}

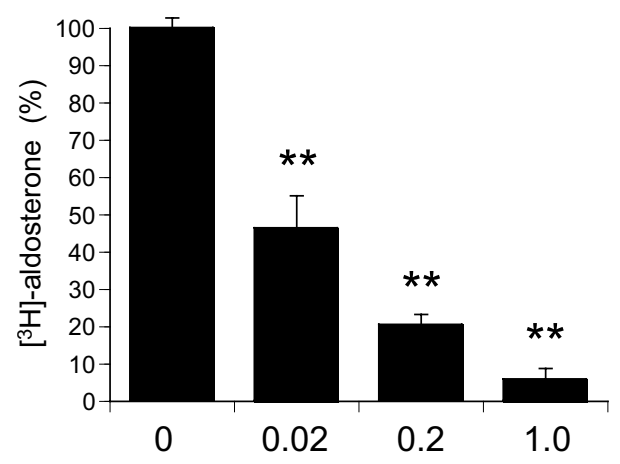

\section{GMGG}

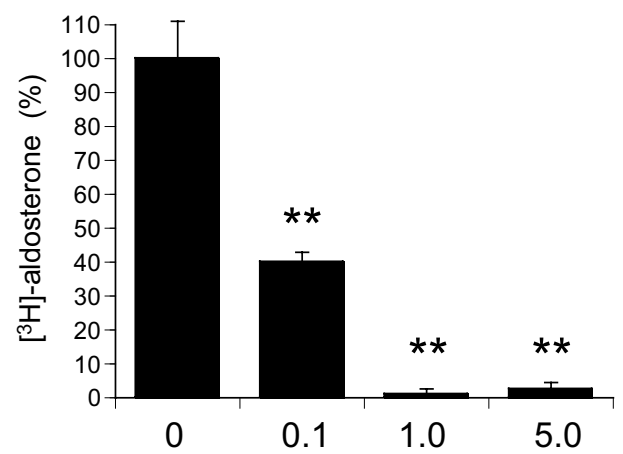

\section{SPIRONOLACTONE $(\mu \mathrm{M})$}

Figure 4 Spironolactone competition for $\left[{ }^{3} \mathrm{H}\right]$-aldosterone binding to the MR LBD and GMGG chimera. Ligand-binding studies were performed in COS-1 transformed monkey kidney fibroblast cells using a concentration of $2 \mathrm{nM}\left[{ }^{3} \mathrm{H}\right]$-aldosterone for the MR LBD and $10 \mathrm{nM}$ $\left[{ }^{3} \mathrm{H}\right]$-aldosterone for the GMGG chimera. The concentrations of spironolactone used were defined by the concentration of $\left[{ }^{3} \mathrm{H}\right]$-aldosterone. Non-specific binding was assessed using a 500 -fold excess of aldosterone. The results are expressed as a percentage of the binding in the absence of spironolactone. The graphs show the mean \pm S.E.M. from the results of two independent experiments $(n=6) .{ }^{\star \star} P<0 \cdot 01$, relative to assay containing no spironolactone.

to the GMGG chimera was $7 \mathrm{nM}$, very similar to the value obtained for the MR LBD. The $\mathrm{IG}_{50}$ value of spironolactone binding to the MGGG was two orders of magnitude lower than that to the MR LBD, confirming the weak binding of spironolactone to this chimera.

The ability of spironolactone to bind to the GMGG chimera was then tested by its ability to compete for $\left[{ }^{3} \mathrm{H}\right]$-aldosterone binding. The $K_{\mathrm{d}}$ value of aldosterone binding to the GMGG chimera is 10-fold greater than for the wild-type MR LBD (Rogerson et al. 1999). To assess spironolactone binding to the wild-type MR LBD, $2 \mathrm{nM}\left[{ }^{3} \mathrm{H}\right]$-aldosterone was used and, for the GMGG chimera, $10 \mathrm{nM}\left[{ }^{3} \mathrm{H}\right]$-aldosterone was used. As shown in Fig. 4, spironolactone was able to compete for $\left[{ }^{3} \mathrm{H}\right]$-aldosterone binding to both constructs. The $\mathrm{IC}_{50}$ values of spironolactone competition for $\left[{ }^{3} \mathrm{H}\right]$-aldosterone binding were calculated as described above (results not shown). The $\mathrm{IC}_{50}$ values of the MR LBD and GMGG chimera were $13 \mathrm{nM}$ and $25 \mathrm{nM}$ respectively. These values were higher than the corresponding $\mathrm{IC}_{50}$ values of spironolactone competition for $\left[{ }^{3} \mathrm{H}\right]$-dexamethasone binding, which reflects the higher affinity of aldosterone for the MR. They were consistent with the above results, showing that spironolactone had a similar affinity for the MR LBD and the GMGG chimera.

\section{MR LBD model}

Using the PR crystal structure, a model of aldosterone-bound MR LBD was generated (Fig. $5 a$ ). The structure consists of $11 \alpha$-helices (although to be consistent with the PR crystal structure the helices are labelled $\mathrm{H} 1$, followed by $\mathrm{H} 3-\mathrm{H} 12$ ) and a $\beta$-turn between helices 5 and 6 . The binding pocket was predicted to consist of 23 amino acids. There are 16 hydrophobic residues in the binding pocket: Leu ${ }^{766}$, Leu ${ }^{769}$, Leu ${ }^{772}$ and $\mathrm{Ala}^{773}$ in helix 3, Trp $^{806}, \mathrm{Met}^{807}$ and Leu ${ }^{814}$ in helix 5, Phe ${ }^{829}$ in the $\beta$-turn, $\mathrm{Met}^{845}$ and $\mathrm{Leu}^{848}$ between helices 6 and 7, $\mathrm{Met}^{852}$ in helix 7, Leu ${ }^{938}$ and Phe ${ }^{941}$ in helix $11, \mathrm{Val}^{954}$ and Phe ${ }^{956}$ between helices 11 and 12 , and Leu ${ }^{960}$ in helix 12. There are six polar residues in the binding pocket: $\mathrm{Asn}^{770}$ and $\mathrm{Gln}^{776}$ in helix 3, Ser $^{810}$ and Ser ${ }^{811}$ in helix 5, and Cys ${ }^{942}$ and Thr ${ }^{945}$ in helix 11 . Finally, there is one positively charged residue in the binding pocket: $\operatorname{Arg}^{817}$ in helix 5 . Figure $5 b$ shows the positions of residues critical for ligand binding. Helix 3 (H3) lies behind the aldosterone molecule in this representation. In this helix, $\mathrm{Asn}^{770}$ is positioned to make hydrogen bonds with the 18- and 21-hydroxyl groups of aldosterone, and $\mathrm{Gln}^{776}$ is positioned to make a hydrogen bond with the 3-keto group of aldosterone as well as a water molecule. Helix 5 (H5) lies in front of aldosterone. In this helix, $\operatorname{Arg}^{817}$ is also positioned 
(a)
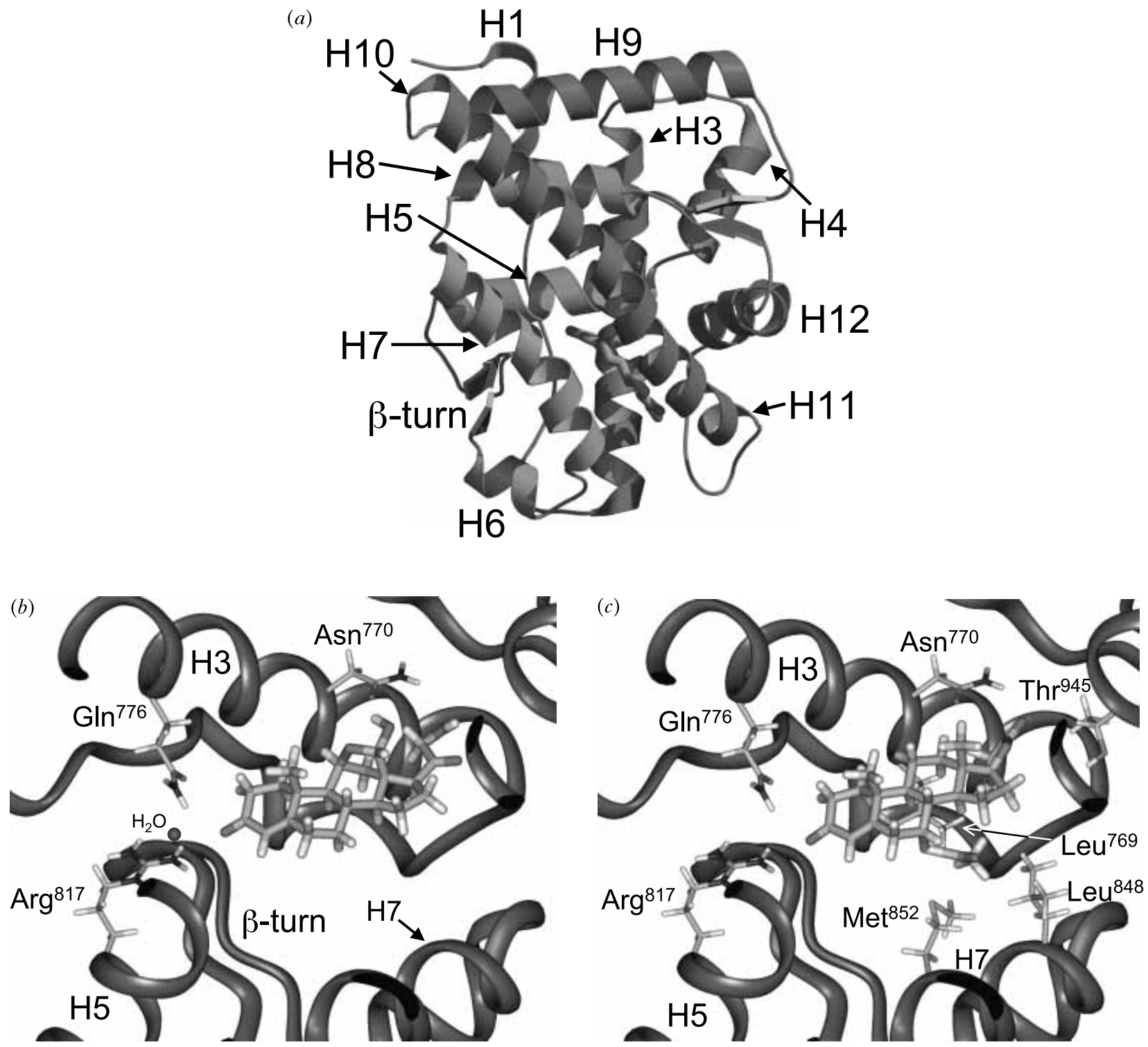

Figure 5 MR LBD model based on the crystal structure of the PR LBD (Williams \& Sigler 1998). Shown are (a) the overall structural elements of the model and the position of aldosterone (amino acids 804-874 are coloured in grey), (b) a close-up of aldosterone binding in the model with the positions of amino acids known to be important for ligand binding and $(c)$ a close-up of spironolactone binding in the model with the positions of amino acids that may interact with the molecule. The helices are numbered as per the published crystal structure of the PR LBD. The figures were prepared using the MOLSCRIPT (Kraulis 1991), Raster3D (Merrit \& Bacon 1997) and Insightll programs.

to make a hydrogen bond with the 3-keto group of aldosterone and the same water molecule. Mutation of these residues has been shown to dramatically decrease the binding affinity of aldosterone (Fagart et al. 1998).

We fitted spironolactone into this model (Fig. $5 c$ ). It was assumed that spironolactone binds in the same orientation as aldosterone and that the 3-keto group of spironolactone forms hydrogen bonds with $\mathrm{Gln}^{776}$ and $\mathrm{Arg}^{817}$. Compared with aldosterone, the steroid backbone structure of spironolactone was displaced approximately $0 \cdot 7 \AA$ away from helices $3(\mathrm{H} 3)$ and $7(\mathrm{H} 7)$. In this position, the $\mathrm{G}_{17}$ lactone ring of spironolactone fits easily into the binding pocket and the carbonyl group is positioned to make contacts with the side-chains of 
$\mathrm{Asn}^{770}$ in helix3 and $\mathrm{Thr}^{945}$ in helix 11. The $\mathrm{G}_{7}$ sulfhydryl ester side-chain projects down from the plane of the page, and fits in between helices 3 and 7. It can make hydrophobic contacts with the side-chains of Leu ${ }^{769}$ from helix 3, and Leu ${ }^{848}$ and $\mathrm{Met}^{852}$ from helix 7 without significant distortion.

Aldosterone and spironolactone binding to the MR LBD was also modelled using the co-ordinates of the more recently published GR LBD crystal structure (Bledsoe et al. 2002) (results not shown). The results did not differ significantly from the modelling based on the PR LBD.

\section{Discussion}

The MR antagonist spironolactone has a much higher affinity for the MR than it does for the GR (Couette et al. 1992b). This has allowed us to use chimeras created between the MR and GR ligandbinding domains to determine sequences in the MR that are important for spironolactone binding specificity. We have previously used the same approach to investigate determinants of aldosterone binding specificity to the MR (Rogerson et al. 1999). Spironolactone competed potently for both $\left[{ }^{3} \mathrm{H}\right]$ dexamethasone and $\left[{ }^{3} \mathrm{H}\right]$-aldosterone binding to the GMGG chimera, demonstrating that the difference in binding affinity of the antagonist to the MR and GR is conferred by amino acids 804-874 of the MR LBD. Interestingly, the same region of the MR contains sequences critical for aldosterone binding specificity (Rogerson et al. 1999). The other three chimeras tested in this study bind dexamethasone but not aldosterone (Rogerson et al. 1999). The MGGG chimera also binds spironolactone, although with an $\mathrm{IC}_{50}$ value two orders of magnitude lower than that of the MR LBD. This result suggested that amino acids $672-803$ of the MR LBD can make a weak, but still significant, contribution to spironolactone binding specificity. In contrast, the lack of binding of spironolactone to the GGMG and GGGM chimeras suggested that amino acids 875984 of the MR LBD are not involved in the difference in spironolactone binding affinity between the MR and GR.

To investigate the interaction of the MR LBD with spironolactone we created models of the MR LBD bound to both spironolactone and aldosterone, based on the published crystal structure of the PR LBD bound to progesterone (Williams \& Sigler
1998). In the model, amino acids 804-874 encompass $\alpha$-helices $5-8$, although helix 8 does not form part of the binding pocket. Helix 5 and the $\beta$-turn lie on opposite sides of the steroid A ring and helix 7 abuts the steroid D-ring (Fig. $5 b$ and $c$ ). In the binding pocket of both the aldosterone- and spironolactone-bound molecules there are two residues that differ between the human MR and GR in this region (corresponding GR amino acids in brackets), $\operatorname{Ser}^{810}$ (Met $\left.{ }^{604}\right)$ and $\mathrm{Leu}^{848}\left(\mathrm{Gln}^{642}\right)$. Serine $^{810}$ can be mutated with no effect on the affinity of aldosterone binding (Fagart et al. 1998). Interestingly, a $\mathrm{Ser}^{810} \rightarrow$ Leu mutation in the MR has been found in eight individuals from the same family with severe early onset hypertension (Geller et al. 2000). One consequence of this mutation is the conversion of spironolactone into an MR agonist in in vitro transactivation assays, but with no apparent effect on binding affinity (Geller et al. 2000). It was concluded that the leucine mutation stabilises the active conformation of LBD by forming a hydrophobic interaction with $\mathrm{Ala}^{773}$ on helix 3 of the protein (Geller et al. 2000). Leucine ${ }^{848}$ of the MR corresponds to $\mathrm{Gln}^{642}$ of the GR. In the crystal structure of the GR LBD, this residue interacts with the $17 \alpha$-hydroxyl group of dexamethasone (Bledsoe et al. 2002). It was proposed from the GR crystal structure that steroids lacking a $17 \alpha$-hydroxyl, such as spironolactone and aldosterone, will bind with low affinity to the GR because of the absence of this hydrogen bond (Bledsoe et al. 2002). However, corticosterone has the same affinity for the human GR as cortisol (Lind et al. 2000), but also lacks the $17 \alpha$-hydroxyl group, arguing against this hypothesis. In the spironolactone-bound structure, Leu ${ }^{848}$ is positioned to interact with the $\mathrm{G}_{7}$ sulfhydryl-ester side-chain. It is unlikely, however, that $\mathrm{Leu}^{848}$ is critical for the binding specificity of spironolactone, as a glutamine residue appears in this position in the AR, which has a high affinity for spironolactone (Corvol et al. 1975).

The inability of the MR LBD model to identify residues involved in binding specificity suggested that the difference in the affinity of spironolactone for the MR and GR is conferred by amino acids in the (804-874) region of the MR LBD that do not interact directly with the ligand. There are precedents for this type of effect in other steroid hormone receptors. The specificity of dexamethasone binding to the GR involves two residues, Asp $^{641}$ and Leu ${ }^{647}$ (Robin-Jagerschmidt et al. 2000), 
that do not interact directly with the ligand in the GR LBD crystal structure (Bledsoe et al. 2002). Similarly, the binding of the progestin RU27987 to the $\mathrm{PR}$ is conferred, in part, by a serine residue that lies on the surface of the receptor (RobinJagerschmidt et al. 2000). The guinea pig GR has a decreased affinity for glucocorticoids, due to amino acid differences with the human sequence that occur in a region that again does not form part of the ligand-binding pocket (Keightley et al. 1998). It is, of course, possible that binding specificity is conferred by amino acids in the MR ligand binding pocket that were not identified in the model, which was based on the PR LBD crystal structure. Because of this possibility, we subsequently modelled the MR LBD using the recently available co-ordinates of the GR LBD crystal structure (Bledsoe et al. 2002). It is very likely that the MR $\mathrm{LBD}$ is closest in structure to the GR LBD, given that the two proteins share $57 \%$ amino acid identity in this domain. The amino acids that form the binding pocket in this model are identical to those that form the binding pocket in the model based on the PR LBD (results not shown).

The result of the MGGG chimera has demonstrated that amino acids 673-803 of the MR make a weak contribution to spironolactone binding specificity. In the MR LBD model, amino acids 672-803 encompass $\alpha$-helices 1, 3 and 4, although only helix 3 contributes to the ligand-binding pocket. Helix 3 forms one face of the pocket and is positioned to make interaction with the $\mathrm{A}, \mathrm{C}$ and $\mathrm{D}$ rings of aldosterone and spironolactone, as well as the lactone ring of spironolactone (Fig. 5). There are two residues that differ between the human MR and GR in this region (corresponding GR amino acids in brackets), Leu ${ }^{766}\left(\mathrm{Met}^{560}\right)$ and $\mathrm{Ala}^{773}\left(\mathrm{Gly}^{567}\right)$. Mutagenesis and molecular modelling studies demonstrate that $\mathrm{Ala}^{773}$ sterically inhibits the binding of $11 \beta$-substituted spirolactones to the MR (Auzou et al. 2000). Spironolactone itself, however, contains no substituent at $\mathrm{C}_{11}$, so $\mathrm{Ala}^{773}$ is unlikely to be involved in binding specificity of the antagonist. Interestingly, Leu ${ }^{766}$ is conserved in the AR, but not in the GR. In the MR LBD model, Leu ${ }^{766}$ lies in close proximity to the lactone ring of spironolactone (results not shown). It is therefore possible that $\mathrm{Leu}^{766}$ contributes to the binding specificity of spironolactone, although its contribution will be small, due to the weak nature of spironolactone binding to the MGGG chimera.
A feature of MR antagonists is the presence of a $\mathrm{C}_{7}$ side-chain. In vivo, spironolactone is converted to canrenone by the cleavage of this side-chain. Canrenone has a 10-fold lower affinity than spironolactone for the MR (Corvol et al. 1981). Therefore, hydrophobic interactions of the $\mathrm{G}_{7}$ sulfhydryl-ester side-chain with Leu ${ }^{769}, \mathrm{Leu}^{848}$ and $\mathrm{Met}^{852}$, predicted from the model, appear to be important for the affinity of spironolactone for the MR, although they do not account for binding specificity. In vivo canrenone is in equilibrium with the open E-ring metabolite canrenoate, in which the lactone ring has been cleaved to form a carboxylic acid. Canrenoate has a very low affinity for the MR (Corvol et al. 1981). Modelling of canrenoate binding (results not shown) suggests that the carboxylate oxygens could form hydrogen bonds with the sidechain atoms of $\mathrm{Thr}^{945}$ and Asn ${ }^{770}$. Binding of canrenoate, however, is unlikely to be energetically favourable, as there is no compensatory positive charge in the protein (i.e. an arginine or lysine) in the vicinity to match the negative charge of the carboxylate. This may explain the very low affinity of canrenoate binding to the receptor.

In summary, the same region of the MR LBD, encompassing amino acids 804-874, is critical for the binding specificity of the synthetic antagonist spironolactone and the natural ligand aldosterone. Modelling of the MR LBD bound to the two ligands suggests that this region forms part of the ligand-binding pocket; however, we were unable to identify amino acids in this region that may be important for binding specificity. Further work using MR:GR chimeras will be needed to identify the individual amino acids that confer ligand binding specificity in the MR. The results of the RALES trial (Pitt et al. 1999), using spironolactone, and the recently completed EPHESUS trial (Pitt et al. 2003), using the related MR antagonist eplerenone, demonstrate the therapeutic benefit of MR antagonists in the treatment of heart failure. An understanding of the binding of spironolactone to the MR may prove to be very useful in the development of new receptor antagonists for use in the treatment of heart failure and hypertension.

\section{Acknowledgements}

This work was supported by research grants from the National Health and Medical Research Council (no. 122200), the National Heart Foundation (no. 
G97 M 4950) and the Pharmacia Corporation, and by a generous donation from Mr \& Mrs Les and Eva Erdi. The authors would like to thank Professor Peter Colman for critically reading the manuscript.

\section{References}

Arriza JL 1991 Aldosterone action: perspectives from the cloning of the mineralocorticoid receptor. In Aldosterone: Fundamental Aspects, pp 13-21. Eds JP Bonvalet, N Farman \& M Lombès. Paris: Colloque INSERM/John Libbey Eurotext.

Arriza JL, Weinberger C, Cerelli G, Glaser TM, Handelin BL, Housman DE \& Evans RM 1987 Cloning of human mineralocorticoid receptor complementary DNA: structural and functional kinship with the glucocorticoid receptor. Science 237 268-275.

Auzou G, Fagart J, Souque A, Hellal-Lévy C, Wurtz J-M, Moras D \& Rafestin-Oblin M-E 2000 A single amino acids mutation of Ala-773 in the mineralocorticoid receptor confers agonist properties to $11 \beta$-substituted spirolactones. Molecular Pharmacology 58 684-691.

Bledsoe RK, Montana VG, Stanley TB, Delves CJ, Apolito CJ, McKee DD, Consler TG, Parks DJ, Stewart EL, Willson TM, Lambert MH, Moore JT, Pearce KH \& Xu HE 2002 Crystal structure of the glucocorticoid receptor ligand binding domain reveals a novel mode of receptor dimerization and coactivator recognition. Cell $11093-105$.

Corvol P, Michaud A, Menard J, Freifeld M \& Mahoudeau J 1975 Antiandrogenic effect of spirolactones: mechanism of action. Endocrinology 97 52-58.

Corvol P, Claire M, Oblin ME, Geering K \& Rossier B 1981 Mechanism of the antimineralocorticoid effects of spirolactones. Kidney International $201-6$.

Couette B, Lombès M, Baulieu E-E \& Rafestin-Oblin M-E $1992 a$ Aldosterone antagonists destabilize the mineralocorticoid receptor. Biochemical Fournal 282 697-702.

Couette B, Marsaud V, Baulieu E-E, Richard-Foy H \& Rafestin-Oblin M-E $1992 b$ Spironolactone, an aldosterone antagonist, acts as an antiglucocorticoid on the mouse mammary tumor virus promoter. Endocrinology 130 430-436.

Doggrell SA \& Brown L 2001 The spironolactone renaissance. Expert Opinion on Investigational Drugs 10 943-954.

Eisen LP \& Harmon JM 1986 Activation of the rat kidney mineralocorticoid receptor. Endocrinology 119 1419-1426.

Fagart J, Wurtz J-M, Souque A, Hellal-Levy C, Moras D \& Rafestin-Oblin M-E 1998 Antagonism in the human mineralocorticoid receptor. EMBO fournal 17 3317-3325.

Funder JW, Pearce PT, Smith R \& Smith AI 1988 Mineralocorticoid action: target tissue specificity is enzyme, not receptor, mediated. Science 242 583-585.

Fuse H, Kitagawa H \& Kato S 2000 Characterization of transactivational property and coactivator mediation of rat mineralocorticoid receptor activation function-1 (AF-1). Molecular Endocrinology 14 889-899.

Geller DS, Farhi A, Pinkerton N, Fradley M, Moritz M, Spitzer A, Meinke G, Tsai FTF, Sigler PB \& Lifton RP 2000 Activating mineralocorticoid receptor mutation in hypertension exacerbated by pregnancy. Science 289 119-123.

Giannoukos G, Silverstein AM, Pratt WB \& Simons SS Jr 1999 The seven amino acids (547-553) of rat glucocorticoid receptor required for steroid and hsp90 binding contain a functionally independent LXXLL motif that is critical for steroid binding. Fournal of Biological Chemistry 274 36527-36536.

Govindan MV \& Warriar N 1998 Reconstitution of the N-terminal transcription activation function of human mineralocorticoid receptor in a defective human glucocorticoid receptor. Fournal of Biological Chemistry 273 24439-24447.
Hong H, Kohli K, Garabedian MJ \& Stallcup MR 1997 GRIP1, a transcriptional coactivator for the AF-2 transactivation domain of steroid, thyroid, retinoid and vitamin D receptors. Molecular and Cellular Biology 17 2735-2744.

Keightley M-C, Curtis AJ, Chu S \& Fuller PJ 1998 Structural basis of cortisol resistance in the guinea pig glucocorticoid receptor. Endocrinology 139 2479-2485.

Knutti D, Kaul A \& Kralli A 2000 A tissue-specific coactivator of steroid receptor, identified in a functional yeast screen. Molecular and Cellular Biology 20 2411-2422.

Kraulis PJ 1991 MOLSCRIPT: a program to produce both detailed and schematic plots of protein structures. Applied Crystalography $\mathbf{2 4}$ 946-950.

Lind U, Greenidge P, Gillner M, Koehler KF, Wright A \& Carlstedt-Duke J 2000 Functional probing of the human glucocorticoid receptor steroid-interacting surface by site-directed mutagenesis: Gln-642 plays an important role in steroid recognition and binding. Fournal of Biological Chemistry 275 19041-19049.

Liu W, Wang J, Yu G \& Pearce D 1996 Steroid receptor transcriptional synergy is potentiated by disruption of the DNA-binding domain dimer interface. Molecular Endocrinology 10 1399-1406.

Merrit EA \& Bacon DJ 1997 Raster3D: photorealistic molecular graphics. Methods in Enzymology 277 505-524.

Nemoto T, Ohara-Nemoto Y, Sato N \& Ota M 1993 Dual role of $90-\mathrm{kDa}$ heat shock protein in the function of the mineralocorticoid receptor. Fournal of Biochemistry 113 769-775.

Pitt B, Zannad F, Remme WJ, Cody R, Castaigne A, Perez A, Palensky J \& Wittes J 1999 The effect of spironolactone on morbidity and mortality in patients with severe heart failure. New England Journal of Medicine 341 709-717.

Pitt B, Remme W, Zannad F, Neaton J, Martinez F, Roniker B, Bittman R, Hurley S, Kleiman J \& Gatlin M 2003 Eplerenone, a selective aldosterone blocker, in patients with left ventricular dysfunction after myocardial infarction. New England Journal of Medicine 348 1309-1321.

Robin-Jagerschmidt C, Wurtz J-M, Guillot B, Gofflo D, Benhamou B, Vergezac A, Ossart C, Moras D \& Philibert D 2000 Residues in the ligand binding domain that confer progestin or glucocorticoid specificity and modulate the receptor transactivation capacity. Molecular Endocrinology 14 1028-1037.

Rogerson FM \& Fuller PJ 2000 Mineralocorticoid action. Steroids 65 $61-73$.

Rogerson FM, Dimopoulos N, Sluka P, Chu S, Curtis AJ \& Fuller PJ 1999 Structural determinants of aldosterone binding selectivity in the mineralocorticoid receptor. Fournal of Biological Chemistry 274 36305-36311.

Roux S, Térouanne B, Balaguer P, Jausons-Loffreda N, Pons M, Chambon P, Gronemeyer H \& Nicolas J-C 1996 Mutation of isoleucine 747 by a threonine alters the ligand responsiveness of the human glucocorticoid receptor. Molecular Endocrinology 10 1214-1226.

Rupprecht R, Arriza JL, Spengler D, Reul JMHM, Evans RM, Holsboer F \& Damm K 1993a Transactivation and synergistic properties of the mineralocorticoid receptor: relationship to the glucocorticoid receptor. Molecular Endocrinology 7 597-603.

Rupprecht R, Reul JMHM, van Steensel B, Spengler D, Söder M, Berning B, Holsboer F \& Damm K $1993 b$ Pharmacological and functional characterization of human mineralocorticoid and glucocorticoid receptor ligands. European Fournal of Pharmacology 247 $145-154$.

Williams SP \& Sigler PB 1998 Atomic structure of progesterone complexed with its receptor. Nature 393 392-396.

Received in final form 17 April 2003

Accepted 12 August 2003 